\title{
Collocated Sharing of Presentations of Self in Public Settings
}

\author{
Felix Anand Epp \\ Aalto University \\ Espoo, Finland \\ felix.epp@aalto.fi
}

\author{
Ilyena Hirskyj-Douglas \\ Aalto University \\ Espoo, Finland \\ ilyena.hirskyj-douglas@aalto.fi
}

\author{
Maria Karyda \\ Aalto University \\ Espoo, Finland \\ maria.karyda@aalto.fi
}

\author{
David McGookin \\ Andrés Lucero \\ Aalto University \\ Aalto University \\ Espoo, Finland \\ david.mcgookin@gmail.com \\ Espoo, Finland \\ lucero@acm.org
}

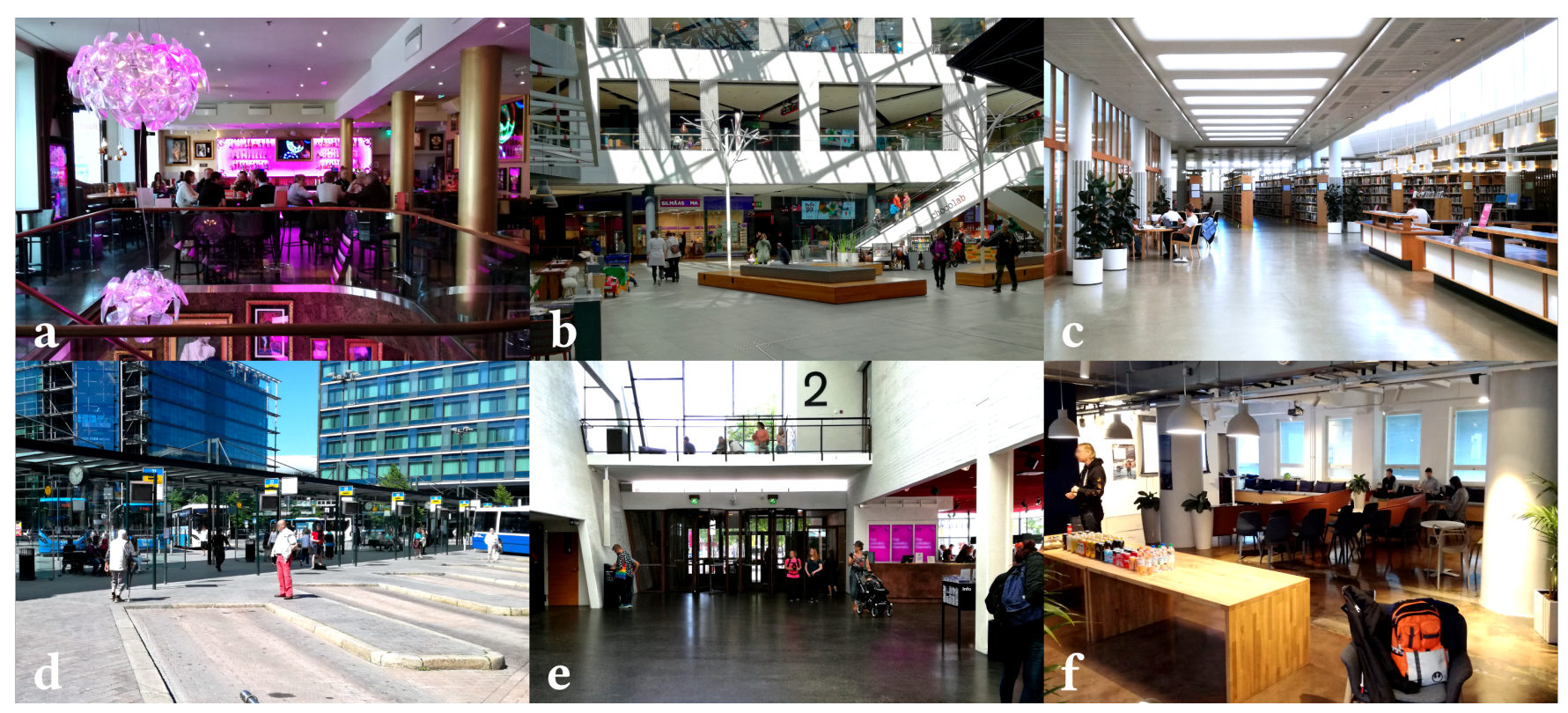

Figure 1: The six field sites: (a) a meetup of travellers in a bar, (b) a shopping centre, (c) a university library, (d) a bus station, (e) a museum and (f) a technology meet up in an office space. See section 3.1 or table 1 for details

\begin{abstract}
Various mobile technologies proofed to enhance peoples collocated social interactions. In particular, user-generated presentations of self have proven beneficial, albeit in specific social settings. This field study interviewed 30 participants for their attitudes towards personal sharing in six public settings in a Nordic metropolitan area. We asked participants to draw what they want to share on an attachable paper sticker. We observed retention towards sharing in places with a more heterogeneous audience. Predominantly people's attitudes towards sharing depended on an individual's current context. Our results highlight the symbolic act of sharing in public
\end{abstract}

\section{(2) $\odot \Theta(\Theta$}

This work is licensed under a Creative Commons Attribution-NonCommercialShareAlike International 4.0 License.

MUM 2020, November 22-25, 2020, Essen, Germany

(C) 2020 Copyright held by the owner/author(s).

ACM ISBN 978-1-4503-8870-2/20/11.

https://doi.org/10.1145/3428361.3428380 as a factor for placing personal public displays. Further, we suggest leveraging the different strategies of extroverts and introverts for collocated social interactions.

\section{CCS CONCEPTS}

- Human-centered computing $\rightarrow$ Field studies; Empirical studies in collaborative and social computing; Empirical studies in ubiquitous and mobile computing.

\section{KEYWORDS}

Augmented Reality, Wearable Computing, Personal Public Displays, Social Context, Self-presentation, Personal Information, Face-toface Interaction

\section{ACM Reference Format:}

Felix Anand Epp, Ilyena Hirskyj-Douglas, Maria Karyda, David McGookin, and Andrés Lucero. 2020. Collocated Sharing of Presentations of Self in Public Settings. In 19th International Conference on Mobile and Ubiquitous Multimedia (MUM 2020), November 22-25, 2020, Essen, Germany. ACM, New York, NY, USA, 10 pages. https://doi.org/10.1145/3428361.3428380 


\section{INTRODUCTION}

Recently, ubiquitous technologies have be used to improve the quality of individuals' social interactions through displaying personal information to nearby others [40]. Such situated displays can create new encounters between strangers or support communication between peers $[10,36]$. While some systems share information to collocated others automatically [23, 39], researchers have also looked at people sharing their self-curated information (images/text) [2729]. These public, yet personal display systems appear in the form of augmented personal objects (e.g., coffee mugs [27], handheld devices [21] and tabletops [28]), as well as wearable technology (e.g., smartwatches [30, 44], head-mounted displays [29, 30], wearable displays [24, 50] or commercial fashion accessories [32, 45, 52]). As preferences for certain technologies distort the experiences of collocated social interactions [18] our primary goal was to look into people's everyday lives for a broader understanding of collocated sharing.

Despite the possibility of everyday placement of mobile devices, research has rarely investigated collocated sharing over different contexts. Prior work has demonstrated how a place and the roles and relationships in a place $[11,30,35,56]$ impact upon social technology. However, technologies designed for collocated social interactions often focus on one distinct social context [40], frequently academic conferences $[4,10,24,36]$. While there are field studies considering the social context, these only investigated computermediated communication [35, 41] or remotely [22] and not in faceto-face instances. Considering face-to-face interactions and physical appearance consequently requires to investigate collocated sharing as a form of expression through physically displaying or "wearing" [26, 55]. However, wearing expressive digital technology is rarely explored in real-life social context [13, 34]. Therefore, it would be valuable to investigate collocated sharing through personal displays in the "mess" of everyday life [8].

We share the perspective of Dourish \& Bell that the "goal [...] must be to design not simply for settings but also for the processes by which practice and meaning evolve." [8]. Consequently, this study critically reflects on the placement of personal displays for sharing in public by reporting on people's individual contexts through the following research questions:

- RQ1: What are the motivations for or against collocated sharing of personal information in different public settings?

- RQ2: What do people want to display in different public social contexts?

Here we investigate the sharing of personal information across various social contexts. We recruited 30 participants on-site across six different locations (a bus station, a mall, a museum, a library and two meetups) in a Nordic metropolitan area to gain a wide variety of individual experiences. To elicit reflections on personal sharing and wearing personal representations away from technological limitations, we provided participants with a paper sticker and pens to create content themselves and express these visually. Through interviews and observations, we investigate how and why participants used the sticker in their current social context. Based on participants' creations and interview data, we present samples from people's real-life situations along their content and the three categories personal context, relational context and place. From our findings, we discuss the limitations and possibilities that public space brings for collocated sharing and how strategies for an individual's personality and self-expression.

\section{BACKGROUND}

Devices that enable people to "get to know each other" have been a constant topic throughout HCI research [10,36]. However, scholars gave little attention to various contexts, social situations, relationships and locations for devices aimed to support peoples face-to-face interactions. Whilst historically there has been a focus on large public screens [36], more recently these systems have become smaller and embedded into our personal objects that we carry and use: such as laptops [28], mobile phones [23] and to the technology we wear such as watches [30, 44] and head-mounted displays [29]. These recent displays combine the aspects of personal devices with those of public displays. They are personal, as an individual carries and depicts personal information, and public, as everyone in the same location can view them.

\subsection{Context of Collocated Sharing In Public}

A large body of research has been explored towards digital technology to support interaction between collocated people [40], especially through sharing personal media and information in face-toface scenarios $[1,10,28-30,36]$. This information provides what Sacks [49] termed as a "ticket" to start a conversation in a socially acceptable way. Further, technologies also aim to support the awareness of collocated individuals $[1,43]$. This social awareness is present also when people do not actively engage in face-to-face conversations, for example, between strangers in public spaces [15].

Supporting collocated social interactions requires to respect the socio-spatial context, as shown in research on connecting strangers [37]. As Heinemann \& Mitchell [17] argue, in order to engage with others, people need a mutual benefit, a need for belonging. Depending on the social context, individuals also need to limit social interactions. When introducing wearable technology to create more social awareness in public, Paulos \& Goodman [43] highlight the balancing act between increasing social awareness and avoiding unwanted engagements. For instance, in neighbourhoods, there is a balancing act in maintaining friendly relationships with neighbours without becoming friends [31]. These trade-offs exemplify how the social context includes needs for keeping a certain social distance even with technology designed to connect collocated individuals.

A majority of these works supported face-to-face interactions in conference settings [4, 10,36] or work environments [1, 16, 28]. Additionally, laboratory studies for augmenting face-to-face interactions with wearables $[18,29,30]$ or interventions in public places [51] were conducted in a specific context for sharing personal information such as an organised event or a local intervention.

However, research on collocated social interactions demonstrated that people use systems differently depending on the social context of the place $[6,17,28,37]$. Dourish and Bell [8] argue that embedding ubiquitous technology does not make the technology disappear but rather contributes to the complexities that compose 
Table 1: The study locations with categorisation from Mayer et al. [35] and ratio of people that joined our study vs. people we asked to participate in our study

\begin{tabular}{llllr}
\hline Location & Social Context & Place Category & Part. Identifiers & Part. Ratio \\
\hline Weekly Bar Meetup of Internationals & Sociable, Organised event & Social & P1-P5 & \\
Monthly Tech Meetup in Office Space & Sociable, Organised event, Familiar People & Business & P26-P30 & 1:2 \\
University Library Lobby & Sociable, Unorganised event & Educational & P11-P15 & 2:3 \\
Contemporary Art Museum Lobby & Unorganised event, Strangers & Educational & P21-P25 & $1: 4$ \\
Shopping Mall Atrium & Unorganised event, Strangers & Business & P6-P10 & $1: 2$ \\
Central Railway Bus Station & Not Sociable, Unorganised event, Strangers & In Transit & P16-P20 & $1: 16$ \\
\hline
\end{tabular}

the context of our everyday lives. Mayer and colleagues [35] operationlise context of collocated interactions into personal context, relational context and social contexts.

Building upon Mayer et al. [35], we defined personal context as a persons' intrinsic motivations, moods, and preferences of individuals' self-expression and social engagements. From a perspective of sharing information with strangers, studies attested personality as a factor [30,42]. For example, in making digital profiles to share with collocated strangers, more extroverted people presented more information, thus make richer digital profiles, than introverted ones in their digital profile.

Another discovered aspect is the relationship people have with each other, here relational context. Typically, people perform different social roles in different settings, e.g. the role of a neighbour might be incompatible with the role of friend [31]. These different "facets" of identity transfer to computer-mediated communication and people keep those facets separated particularly in stigmatised practices [11]. In wearable displays, people have been concerned about accidental disclosure to collocated people [38]. Here, a critical factor regarding disclosure is people's subjective closeness to someone. Wiese et al. [56] identified closeness as the more significant factor than the location for people's willingness to reveal personal information to others.

Finally, social context, we will call here place, includes the influences of the locality and its social norms. As noted before [56], the familiarity with collocated people increases the willingness to share. Further, a place perceived being suitable for socialising increases the willingness to meet new people [35]. One last factor is the organisational structure of a gathering. Organised events seem to support meeting strangers more than a loose accumulation of individuals [35].

Dourish [7] defines context as a manifestation of people's practices. This view suggests observing context through what people do in a particular setting. For example, people engaged in conversation at a bar define it as a place for socialising. In order to grasp the motivations towards collocated sharing, it is necessary to inquire about people's actions in-situ. In summary, people's motivations based on their social setting is a central theme for investigating social technology [35].

\subsection{Forms of Collocated Sharing}

Previously, mobile technologies have been used for augmenting face-to-face interactions, for example as name tags or badges $[2,10]$. Recent studies have integrated displays in personal objects such as mugs, handbags, bracelets and laptop back-covers [5, 22, 27, 28]. Further, head-mounted displays enable augmented reality to display personal information in the viewer's device [29]. Because physical appearance is a part of face-to-face interactions [14], we have to consider augmentations beyond media. For example augmented reality has also been explored to augment fashion [12, 34, 48]. Other examples for fashionable wearables are the plethora of individual designs in making culture [54], design explorations [13, 22, 46] and commercial wearable display products, such as bracelets $[32,52]$ or buttons pins [45]. In light of fashionable wearables, we gain insights from investigating everyday practices of "wearing" as a form of sharing personality $[53,55]$. Therefore, we consider visual displays in general and not just digital screens in our exploration. Two examples for this would be the handkerchief code used by the gay community as a secret form of communicating sexual preferences and identity [47] or wearing headphones as a barrier to avoid social interactions [20].

\section{STUDY OUTLINE}

In this paper, we conducted a field study with interviews and observations to understand the influence of different social contexts of public life for sharing through a wearable display. To inquire about "wearing" a personal information display, we made use of a known physical artefact: a paper sticker that can be customised easily and applied to participants' clothes. In answering our research questions, we study participants in six public locations. In a design task, participants created personal representations to wear. Afterwards, we interviewed participants about their creations and their motivations and personal context. Finally, a questionnaire captured demographics and information about social context and place. This data is then further reflected upon with the help of field observations captured in these locations. In this section, we describe this procedure in detail.

\subsection{Six Field Sites of Varying Social Context}

The interviews and observations were conducted in six different public locations in the metropolitan area of Helsinki, Finland. To give a cross-cut through public urban life we included public places in the categories from Mayer et al. [35] (see Table 1). The locations were: a meetup of travellers in a bar, a shopping centre, a university library, a bus station, a museum and a technology meet up in an office space. We chose those places for their variation in organisation level and common activities based upon Mayer and colleagues [35] previous findings. 
We chose two meetups to provide the context of an organised event. The weekly international meetup provided paper stickers for its guests to get to know new like-minded people. The monthly professional meetup centred around an open-source software with invited talks and networking afterwards. Further, we chose the library and museum as places without any organised event but as places where people spend time in a particular activity. Lastly, the bus station and shopping mall (which also included community services) represent places with higher fluctuation of people with different activities. Figure 1 displays additional differences in characteristics. We based our choices on categories of places and context by Mayer et al.. Through our questionnaire, we later verified these categorisations seen in table 1.

\subsection{Procedure}

The first author conducted all interviews and observations. The recruiting of participants was done by approaching people directly in the study locations. During recruiting, we captured notes on the times of the events, requests to participate (totalling 208), initial notes on interview results as well as our reflections.

In order to anchor our research in current real-life practices, we choose a paper-based drawing task to elicit sharing without centring the discussion around a particular digital technology. We handed out paper stickers and provided participants with the following instructions: "Create a personal sticker to show others. This sticker is meant to be applied to your clothes, so other people here can see it." In order to understand motivations and affordances, we did not provide a more specific purpose for the sticker. Participants had no time limit in that phase. Each participant spent, on average, three minutes customising their sticker. We left participants to decide if they want to apply the sticker on their clothes. The artefact we chose as a probe was a paper-based $10 \times 7.5 \mathrm{~cm}$ blank white sticker. This form factor required a low level of entry as it was easy to modify with multiple colour pens. The sticker did not serve as an ideal form factor or user interface but a gateway into the conversations about their self-presentation.

Following this drawing task, we interviewed participants with a semi-structured script. The interview focused on the participants' activities before and after our inquiry to capture their individual context. Additionally, we asked about their experience and expectations with people on-site and motivations towards sociability. We then inquired what participants had drawn on the sticker and why. Finally, we asked upon reasons for wearing or not wearing the sticker and about their general attitude towards appearance. Each interview took on average 23 minutes $(S D=8)$, was audio-recorded and later transcribed.

After the interview, we asked participants to fill in a questionnaire capturing their demographics, extroversion and social context, as these are the factors prior studies identified. A self-descriptive sentences questionnaire [25] recorded a personality trait extraversion. We measured the social context by four factors of a place from Mayer and colleagues' framework [35]. The factors public (vs private), sociability, familiarity (vs strangers) offered a rating on a five-point Likert scale. Further, we asked, whether or not they attended an organised event and about their relationship towards

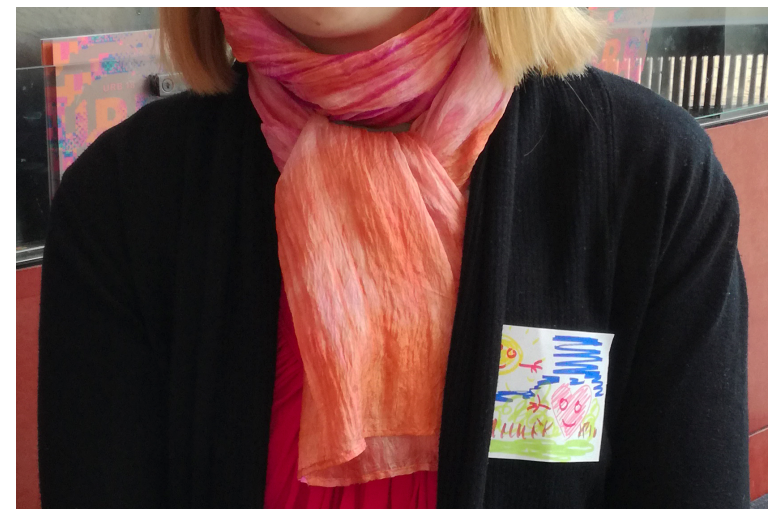

Figure 2: Participant 22 wearing their sticker

familiar people in a free-form field. These factors serve to contrast the participants' interview answers.

In addition to the interviews, we performed non-participant observations in all locations disconnected to the interviews. Through field notes of on-site observations and reflections about the general public and locality, we triangulated our results. This triangulation allowed our data to have an in-depth understanding of the participants' reports, in-situ behaviour and how the participants' thoughts reflected observed behaviour in those places. Observations were conducted for a minimum of 90 minutes at each location, systematically capturing people's actions in the form of scratch notes. These scratch notes formed more extensive field notes summarising emergent themes [9]. The field notes were compared with each other and with the results of the interviews.

\subsection{Analysis}

To analyse the interviews data in depth we used Affinity Diagramming, which is a widely used method in design research and practice-based research $[19,33]$. The investigator in the field and another researcher analysed the interviews (both recordings and transcripts), participants' drawings, field notes, questionnaire results together. All data were labelled and grouped with two additional researchers who joined for two rounds of interpretation. This resulted in an affinity wall consisting of 833 notes. From the initial notes, 158 notes were discarded that did not form or contrast any clusters. The notes formed 84 clusters in 17 categories, that were summarised and counted for individual participants. Finally, the themes from these clusters were filtered for the results in this work based on the research questions.

\subsection{Participants}

We interviewed 30 participants (14 female, 16 male) ageing from 21-48 years $(M=32 \mathrm{SD}=7.6)$. Four participants did not specify their age. We recruited five participants in each location. By selecting participants in an ad-hoc manner on-site, we gained a diverse sample of participants. The interviews spread across seven months (AprilOctober) at different times of the day (between 11:00 and 22:00). Participation required sufficient skills in English, which excluded mostly older population and being above the age of 15 , according to national laws. The length of residency in the metropolitan region 

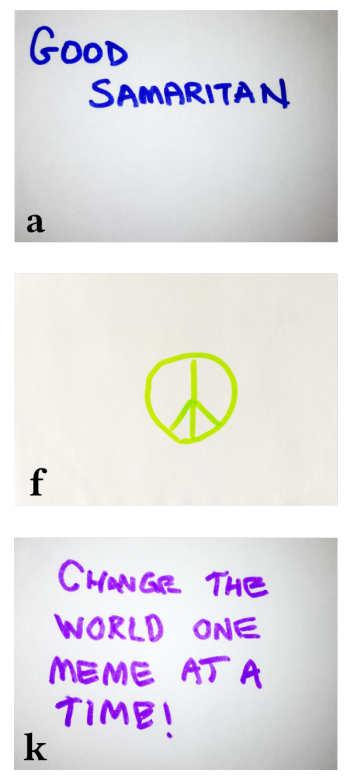
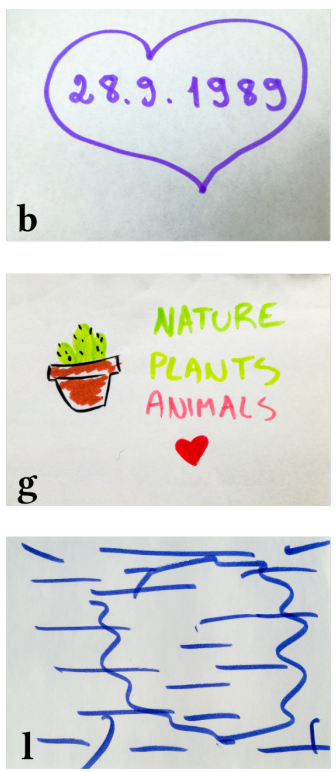
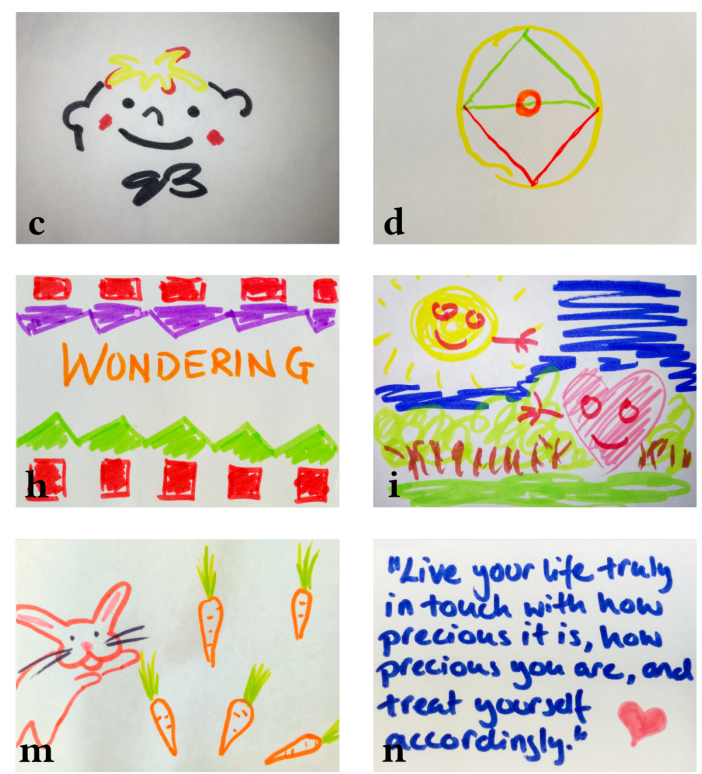
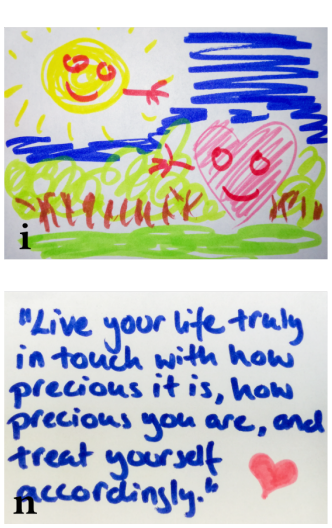
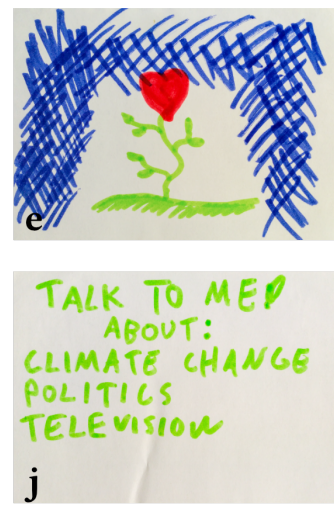

j

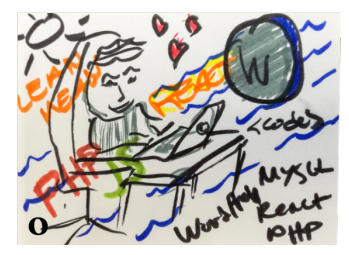

Figure 3: Fifteen stickers created by the participants at the (a,b) mall, (c,d) library, (e-g) bus station, (h-k) museum and (l-o) professionals' meetup. See section Participants' Drawings and Their Use for descriptions of what they depict.

of four participants each was short-term, six to 18 years and more than 18 years, while eight participant's residency was permanent but shorter than six years. For taking part in the study, participants received one cinema voucher (approx. EUR 14). This study was reviewed by the Research Ethics Committee of Aalto University before data collection.

\section{RESULTS}

Our field study sparked very different results, depending on the varied people's contexts. Thirty people participated in the interviews, and two left the drawing task blank. We report our results in four sections. First in section 4.1 we focus on contents of drawings and how people imagine their use differently. Then we report the participants' reasoning for using the artefact along the three contextual categories: their personal context and understanding of self in section 4.2, the relations to others in section 4.3 and aspects about the locality and its influence in section 4.4.

Our main findings show how people represent themselves different by the characteristics of the immediate context and place. Especially, unstructured, heterogeneous places brought reservations towards showing representations of self in public. However, associations about places were individual and ultimately personal differences shaped sharing practices. In particular, the notion of "being introvert" revealed different strategies in using personal representations in public.

\subsection{Participants' Drawings and Their Use}

In the participants' drawings, the most common depictions were either a name $(8 / 30)$ or generic positive motifs, like hearts, smiley faces, suns, flowers and a peace sign (see figure $3 \mathrm{~b}, \mathrm{c}, \mathrm{e}-\mathrm{i}, \mathrm{o}$ ). Three participants drew nothing besides one of these generic symbols (e.g. fig. 3f), others used the sticker to draw something representing their personality (fig. 3e,h,o). For example, the pattern in figure $3 \mathrm{~h}$, illustrates participant 21's preference for simple geometric shapes. Another way of using the sticker described by multiple people was to display personal interests. Only three participants chose to list their interests through text (see figure 3g,j,o) and four only through drawings (see figure $31, \mathrm{~m}$ ) or quotes (see figure $3 \mathrm{k}, \mathrm{h}$ ). Interestingly five participants did not draw anything and left the provided sticker blank. Further, only eight participants applied the sticker to their clothes (see table 2). We discuss the motivations for or against these creations in the following sections.

Almost half of the participants (14/30) rejected to attach their drawing to their clothes because it did not fit their personal style. Drawing on white paper appeared to have a "sketchy", "blank", "unfinished" and "childish" character. Eight participants explained this with their limited drawing skills. They would have preferred photographs or digital tools. The other six reported disliking the drawing format as a "label" and would have preferred sharing about themselves through clothing or textile badges. For example, participants 21 is a proficient illustrator but explains not wearing the sketch of himself in figure 3c as follows: "I don't want to lock myself. [in] being a boy or being a nice guy." However, two participants acknowledged how something they created themselves is of special value to them. Fittingly participants 10,16 and 21 used the available means of selecting a specific colour they like to align their drawing with their choice of clothing (see figure $3 \mathrm{~b}, \mathrm{e}, \mathrm{h}$ )).

Participants often described the format as something resembling a conversation opener (Sacks et al., 1995). Eight participants referred to its resemblance to name tags or conference badges. Additionally, displaying a name on a sticker (8/30), and naming a personal interest (9/30) was seen as a starting point for conversations. These perceptions attribute a function to the sticker initiating face-to-face 
Table 2: This table shows the participants actually wearing a sticker on their clothes (8), not drawing anything on the sticker provided by our study (5) and writing their names (8). ${ }^{*}$ Three participants wore stickers already provided by the event and did not add to that.

\begin{tabular}{lccc}
\hline Location & Wore A Sticker & No drawing & Name on sticker \\
\hline Int. Meetup & P1-P5 & P2, P4, P5* & P1-P5 \\
Pro. Meetup & P28 & - & P26 \\
Museum & P22 & - & - \\
Library & - & P15 & P12 \\
Mall & P10 & P7 & P9 \\
Bus Station & - & - & - \\
\hline Total & 8 & 5 & 8 \\
\hline
\end{tabular}

interactions. Interestingly, participant 7 noted how the sticker interferes with his needs of avoiding interactions due to its function as providing a ticket to open a conversation: "I would [...] lose the option not to talk to someone." This inadequate affordance of a sticker kept four participants from considering to attach their creation on their clothes.

\subsection{Personal Context}

For eleven participants their current state of mind or mood was a source of inspiration for their drawing (fig. 3a,h,i): "obviously I'm in the work-mood at the moment, so what comes to mind is work-related." (P9). The figures 3b,h,i,k, show this tendency with depictions of an occurring birthday, a current feeling, a mood and an idea form a recent project. Further, the primary reasoning behind participants not wanting to be involved in the study were time constraints.

Mostly, however, people did not attribute what they shared to their current personal context but their perception of themselves. The intended uses for the drawing were mainly for sharing personal interests $(9 / 30)$ or more general expressions of self $(10 / 30)$. Participant 20 (see figure $3 \mathrm{~g}$ ) explains the topics of interest in their drawing as "near and dear to [their] heart, but [...] neutral." Only a few participants thought of making a statement as a motivational quote (P29), an awareness shirt/ribbon (P13, P15) or religious conviction 3a. One example of an implicit representation of self is the cartoon face in figure 3c (P12): "that's my signature. I always draw this fat kid as [sic] me."

The motivation for using a personal representation also differed by individual preference. For example, a sticker with only a name can be enough in case people prefer disclosing more information in a conversation. For those, conversations with strangers reveal interesting topics or personal stories, which motivates people to interact. A person at the bus stop (P16) recalled an encounter just before the interview: "there is this element of serendipity [in talking to strangers,] and I really like that". Another example was the idea by P11 to portray people's recent activity in order to be aware of happenings in the area. "If I saw someone coming from some happening or some event, [...] I would ask, 'Was there free beer?' or 'Was it fun? Should I go there? Should I stop being here?'” (P11). One participant (P10) named curiosity as a reference for the decision to apply the sticker to their clothes in the shopping mall: "I hope [...] they are curious and interested." Overall, 16 participants reported a notion of curiosity as a motivation for deciding about their current activities.

Also, more than two-thirds (22/30) of participants directly or indirectly mentioned the notion of being an extrovert or introvert and revealed a difference in strategy. The people referred to themselves as "social", "outgoing" and "talkative" or "shy". These descriptions align with the general tendency towards each end of the extroversion scale of the questionnaire. Only two people contradicted their description in their questionnaire answers. Interestingly these selfperceptions also motivated differences in behaviour. For example, attending the internationals meetup was a way to improve social skills. Participant 2 plans to meet one or two new people every week: "For me, it's a little bit difficult to socialise [...], [...] with these meetups [I try to] break these limits for me." Overall six people spoke of their intent to change: "I hate, that I'm so shy. [...] I will participate [in] some acting course [...].” (P22).

Accordingly, strategies for using the sticker also differed. Participant 23 reported "lots of regrets of situations [...] to meet interesting people, and then passed it on.". For them, the topic interests listed on their sticker would help to match with relevant people and to avoid small talk. They explained how out of politeness "you can't escape quickly" out of a conversation. Contrarily, participant 7 likes to talk, and "[doesn't] need a sticker" to talk to someone.

\subsection{Relational Context}

A name tag attributes a distinct role in the context of a place. In this section, we describe how those roles inspired the content of the drawings. For example, a participant at the professionals' meetup (P26) displayed contact details to be reachable: "then they know who [sic] to talk to." They explained this with their role as one of the organisers of the meetup. Another participant (P22) drew something "childish" in the museum. They stated their reason for visiting the museum as "you have to feel that you are an independent woman or man", in contrast to their routine as a young parent at home. Similarly, participant 15 explained her choice of outfit to "be taken seriously as a young female scholar". Hence, similar to clothing, roles also transferred onto the personal representations.

Similarly, participants' strategies to address privacy concerns also related to the relational context. Twelve participants avoided any information that can identify them. Vagueness and ambiguity of implicit information are strategies employed here to manage disclosure by filling in the details in conversations. For example, P14 avoided making statements: "I don't need to impose anything about this stuff to anyone, only if someone asks I have something to say, then I have to have a conversation." One participant with a middle-eastern background reported using pseudonyms: "I didn't want to show my nationality before. [...] I used another European name [...].” (P4).

Further, P16 acknowledged how closeness might play a role: "We are close enough that [the friend I am meeting soon] would know that this is representative of me". In contrast to avoiding personal identification, people would share contact details in professional meetings, as their primary function is networking. The organiser of the professional event (P26) drew their Twitter handle, and the 
worker in the mall on their lunch-break (P9) drew a hashtag: "[...] this is enough to at least find you on the internet".

The interviewees often reported a need for belonging to a community. In the professional meetup, all participants expressed their affinity to the broader community of the meetup's open-source technology. Participant 30 displayed this in drawing the respective logo on their sticker. In addition to symbols on their drawings, participants referred to other physical symbols of belonging. For example, participant 17 was wearing and referring to a ring that honours his military service. It serves as a shared symbol between him and the service member he had planned to meet. He highlights how this shared symbol has led to others recognising him and starting conversations. Further, participant 15 wore a reflector portraying the logo of the employer, although they were quite conservative about sharing with the sticker. Belonging was also the reason three participants would not want to wear their drawing. They did not want to be the only ones to wear it: "that people see that it's not just me; it is other people too." (P23) Likewise, an attendant of the internationals' meetup (P1) describes wearing the sticker outside of the event as "a little bit of a fuck you statement, [because] I don't care about what you think".

During the professional meetup, the mainly male audience dressed in a typical style of hoodies, sporting apparel and similar short haircuts. Participant 24 illustrates that "[...] hoodies are connected, today, to [the] tech scene. [...] It's an informal uniform." Likewise, students interviewed in the library related to the people around them, as similar because they are also students. This sense of community was seen positively for different levels of engagement. The three levels that participants reported were: meeting a community of known people, meeting new people related to one's interests but also just being around similar people without actively engaging. Fittingly, three participants wanted to make people appreciate each other (P17, P19, P29), because of their festive mood. Participant 18 explained it like this: "I just felt that everybody is happy and we can be happy together". A similar case of reciprocity was the idea of asking or offering help (P6, P7).

\subsection{Place}

The places of our study form groups by their common characteristics: both meetups were organised events and social, mall and bus station were busy with a heterogeneous crowd and museum and library were unorganised but had a more homogeneous crowd. Participants attested all locations as public (27/30) or semi-public places (3/30).

Everyone at both meetups (10) rated those as places to socialise, and apart from one participant at the internationals' meetup everybody knew some of the people on-site. The networking event focused on a software system and the other on travel and cultural exchange, however, participants described the attendees as a mix of different people. Participants praised the meetups' sense of community and open-mindedness (5/10). Attendants acknowledged this openness positively: "to be yourself and authentic" (P29). The organisers of the internationals' meetup provided stickers and instructions to wear a sticker with name and country. We observed all event participants following those instructions and wearing a sticker. Only one of the five participants did see the need to draw something else. However, this name- and nationality tag was acknowledged as setting-specific and prone to misinterpretations. One participant rejected the idea of sharing their nationality outside the meetup because it would portray them as "a proud nationalist" (P1).

Two participants at the museum and three at the university library mentioned them as places for focused activities, but also as meeting places. In the museum and the library, some participants focused on the art (P22) or their studies (P11, P12, P13), respectively. The library participants perceived people on-site as a homogeneous group of students. Two participants, themselves students, attested some familiarity with others, and three participants rated their location as a place to socialise. While the purpose of the library seemed to structure the place, the participants at the museum felt they were among strangers. Similarly, the mall and the bus station were places filled with strangers, and none of the participants could describe a particular type of person to expect on-site. Two out of the five participants at the mall $(2 / 5)$ and three our of five at the bus stop (3/5) described them as busy. In the mall, people reported avoiding people because of sales personnel (P8), "taking a social break" (P9) or "finish[ing] some business" (P7). Both locations had by far the most interview refusals (see table 1 ).

These distinctions between places are essential as thirteen participants stated how the sticker content depends on the event or place they attended. In the community event, the tag functioned as a symbol of membership. In the mall, the name tag of P9 implied a work-related role. Such associations about place determined the reservations about sharing publicly. Insofar the place influenced public sharing, however, based on each individuals interpretation of it.

\section{DISCUSSION}

In this section, we relate our findings to previous work on collocated social interactions. Although our results show use cases for sharing in public, the reservations towards displaying their drawings highlight the importance of context-sensitivity. Especially for the individual differences between participants, this includes not just the contents, but the symbolic meaning of showing personal representations in public.

\subsection{Individual Strategies for Collocated Personal Sharing}

Participants interpreted the use for their drawings in different ways, which adds use cases for expressive wearable displays. Similar to the approaches applied in prior work [40], many participants interpreted the sticker as generating an opening to allow others to engage them in conversation by displaying their name, interests or attractive symbols, or increasing awareness between them and others around them. Noteworthy was here an idea of asking or offering help. Further, our study revealed that people employ different strategies to use an artefact based on their self-perceived extroversion. Some participants with introvert tendencies seemed to plan their encounters more carefully and saw the sticker as helpful in this accord. Contrary to this, more extrovert participants seemed to plan their social encounters without or only minimal need for such an artefact. Prior research had revealed that extroverts share 
more information in their profiles when augmenting conversations in face-to-face meetings [30]. However, similar to work on topic suggestions in conversations [39], our study hints towards the use of such information was less valuable to extroverts, as they do not need such support in conversations. Therefore, we see one opportunity in designing for supporting introverts in managing their social interactions. As a consequence future collocated sharing systems should support individual strategies, instead of employing generic approaches.

\subsection{Willingness to Share a Personal Representations In Public}

Our study reveals, how a public representation of self attributes a temporary ritual state [14] to the wearer. The internationals' bar event inclined guests to wear a sticker and therefore attached a definite meaning to wearing their sticker: being a participant of the meetup. In other locations, such a specific meaning for the drawing lacked with participants often reporting that wearing a sticker would feel out of place. In these locations, the number of people displaying their creation was low (3/25). However, participants did not attribute their decisions on privacy concerns. As apparent in figure 3, most of the peoples' creations contained only implicit or ambiguous information. People explained their willingness to share the information depicted in their drawings but still refused the idea to show it on-site. The name-tag association invites for conversations and therefore interferes with people's needs to avoid social interactions [31, 43]. Especially in more heterogeneous crowds (mall and bus station), this need to limit interactions was apparent. This need might result from, what Erving Goffman called civil inattention, i.e. to share a public place between strangers without imposing on others [15]. Recent work on collocated social matching has addressed this challenge with designs that gradually reveal information and ensuring anonymity by progressing from mediated anonymous communication to face-to-face interactions [41, 51]. Our results suggest that also expressive forms of sharing could benefit from systems that allow for a gradual reveal. At least, a system that allows for sharing personal content publicly, for example, wearable displays, would have to allow for a level of control that allows maintaining civil inattention.

As the act of sharing personal information in public becomes part of one's appearance, this act communicates social status. According to Goffman, this includes a "temporary ritual state, that is, whether [they are] engaging in formal social activity, work, or informal recreation [...]". This act of sharing one's current activity seemed to be the predominant factor in people's reasoning. Our findings raise the importance of such symbolic, not just topical, the meaning of displaying personal information publicly. The aspect of community and group belonging is a constant theme throughout our findings. We know people manage their impression towards others according to the people they are with [11]. However, considering symbolic meaning, we can draw from fashion as "the imaginary sense of belonging, [... to] execute self-expression as a member of a desired social group" $[3,53]$. Accordingly, any technology that becomes part of self-expression needs to address social groups beyond the current setting. Most design objectives for supporting face-to-face interactions, like increasing awareness or breaking ice in new encounters [40] have focused on design approaches with discrete interactions (e.g. topic suggestions [39]). As self-expression serves more than as a means to translate to more discrete interactions [14], a promising approach would be to design new forms of augmenting self-expression. This approach might generate opportunities for collocated social interactions through serendipitous encounters.

\subsection{Limitations and Future Work}

This study has collected accounts of using public sharing over different settings and different participants. Therefore, the personal reporting of our participants might be biased towards social desirability, locality and personal viewpoints and is embedded within the time and place and current societies perspective upon ubiquitous technology. However, these subjective experiences help in situating the research in real-life collocated scenarios but would benefit from investing this over different countries, cultures and societies. It is also worth noting that our study did not investigate a particular design or technology, and our drawing task itself was limited to static content. While this allows us to investigate viewpoints away from technology affordances, further work could be looking at how wearable displays could become dynamic. Dynamic displays additionally would also address context-sensitive issues, noted within this paper. It is also plausible that some practices of online sharing were transferred over into peoples thoughts and attitudes towards wearable displays. Thus, future work is required to place artefacts within people's lives over time to observe what people actually will do in practice.

\section{CONCLUSION}

This work investigated motivations and practices on sharing representations of self in different real-life public contexts of a Nordic metropolitan area. We reported how people's attitude towards sharing personal information in public differed by their immediate context and place. In particular, places with less structure and heterogeneous crowds brought retention towards sharing. Still, individual preferences remained, and participant's self-perceived extroversion shaped their collocated sharing strategies. These insights revealed the necessity to consider any personal representation as a form of self-expression and consequently, the challenge of respecting people's need to not impose on others through the act of sharing. Further, we argued that the design of personal wearable displays and other collocated social interaction technology would profit from catering to the needs of introverts and extroverts differently.

\section{ACKNOWLEDGMENTS}

We want to thank the different institutions for their cooperation in collecting data on their premises. Our gratitude also goes to Tapio "Tassu" Takala for his comments on the manuscript. This work was supported by the Academy of Finland project Digital Aura [311090].

\section{REFERENCES}

[1] Susanne Bødker and Ellen Christiansen. 2006. Computer Support for Social Awareness in Flexible Work. Comput Supported Coop Work 15, 1 (Feb. 2006), 1-28. https://doi.org/10.1007/s10606-005-9011-y

[2] Richard Borovoy, Fred Martin, Sunil Vemuri, Mitchel Resnick, Brian Silverman, and Chris Hancock. 1998. Meme Tags and Community Mirrors: Moving from 
Conferences to Collaboration. In Proceedings of the 1998 ACM Conference on Computer Supported Cooperative Work (CSCW' 98 ). ACM, New York, NY, USA, 159-168. https://doi.org/10.1145/289444.289490

[3] Pierre Bourdieu. 1977. Outline of a Theory of Practice (25. printing ed.). Number 16 in Cambridge Studies in Social and Cultural Anthropology. Cambridge Univ. Press, Cambridge.

[4] Jay Chen and Azza Abouzied. 2016. One LED Is Enough: Catalyzing Face-to-Face Interactions at Conferences with a Gentle Nudge. In Proceedings of the 19th ACM Conference on Computer-Supported Cooperative Work \& Social Computing - CSCW '16. ACM Press, San Francisco, California, USA, 172-182. https://doi.org/10.1145/ 2818048.2819969

[5] Ashley Colley, Minna Pakanen, Saara Koskinen, Kirsi Mikkonen, and Jonna Häkkilä. 2016. Smart Handbag as a Wearable Public Display - Exploring Concepts and User Perceptions. In Proceedings of the 7th Augmented Human International Conference 2016 on - AH '16. ACM Press, Geneva, Switzerland, 1-8. https: //doi.org/10.1145/2875194.2875212

[6] Lisa G. Cowan, Nadir Weibel, William G. Griswold, Laura R. Pina, and James D. Hollan. 2012. Projector Phone Use: Practices and Social Implications. Personal and Ubiquitous Computing 16, 1 (2012), 53-63. https://doi.org/10.1007/s00779011-0377-1

[7] Paul Dourish. 2004. What We Talk about When We Talk about Context. Personal and Ubiquitous Computing 8, 1 (Feb. 2004), 19-30. https://doi.org/10.1007/s00779003-0253-8

[8] Paul Dourish and Genevieve Bell. 2011. Divining a Digital Future: Mess and Mythology in Ubiquitous Computing. MIT Press, Cambridge, Mass. http:// ebookcentral.proquest.com/lib/aalto-ebooks/detail.action?docID $=3339242$

[9] Robert M. Emerson, Rachel I. Fretz, and Linda L. Shaw. 2011. Writing Ethnographic Fieldnotes. University of Chicago Press.

[10] Jennica Falk and Staffan Björk. 1999. The BubbleBadge: A Wearable Public Display. CHI'99 extended abstracts on Human factors in computing systems (1999), 318-319. https://doi.org/10.1145/632716.632909

[11] Shelly D. Farnham and Elizabeth F. Churchill. 2011. Faceted Identity, Faceted Lives: Social and Technical Issues with Being Yourself Online. In CSCW' 11. ACM 359-368. http://dl.acm.org/citation.cfm?id=1958880

[12] Anna Fuste and Chris Schmandt. 2018. ARTextiles for Promoting Social Interactions Around Personal Interests. In Extended Abstracts of the 2018 CHI Conference on Human Factors in Computing Systems - CHI '18. ACM Press, Montreal QC, Canada, 1-6. https://doi.org/10.1145/3170427.3188589

[13] Çağlar Genç, Oğuz Turan Buruk, Oğuzhan Özcan, Sejda Inal Yilmaz, and Kemal Can. 2017. Forming Visual Expressions With Augmented Fashion. Visual Communication 16, 4 (Nov. 2017), 427-440. https://doi.org/10.1177/1470357217714652

[14] Erving Goffman. 1959. The Presentation of Self in Everyday Life (nachdr. ed.). Doubleday, New York, NY.

[15] Erving Goffman. 1966. Behavior in Public Places: Notes on the Social Organization of Gatherings (1. paperback ed., 24. printing ed.). The Free Press, New York, NY.

[16] Jonna Häkkilä, Romina Poguntke, Emmi Harjuniemi, Lauri Hakala, Ashley Colley, and Albrecht Schmidt. 2020. BuSiNec - Studying the Effects of a Busyness Signifying Necklace in the Wild. In Proceedings of the 2020 ACM Designing Interactive Systems Conference (DIS '20). Association for Computing Machinery, Eindhoven, Netherlands, 2177-2188. https://doi.org/10.1145/3357236.3395455

[17] Trine Heinemann and Robb Mitchell. 2013. Breaching Barriers to Collaboration in Public Spaces. In Proceedings of the 8th International Conference on Tangible, Embedded and Embodied Interaction - TEI '14. ACM Press, Munich, Germany, 213-220. https://doi.org/10.1145/2540930.2540951

[18] Ilyena Hirskyj-Douglas, Mikko Kytö, and David McGookin. 2019. Head-Mounted Displays, Smartphones, or Smartwatches? - Augmenting Conversations with Digital Representation of Self. Proc. ACM Hum.-Comput. Interact. 3, CSCW (Nov 2019), 179:1-179:32. https://doi.org/10.1145/3359281

[19] Karen Holtzblatt, Jessamyn Burns Wendell, and Shelley Wood. 2004. Rapid Contextual Design: A How-to Guide to Key Techniques for User-Centered Design. Elsevier.

[20] Mizuko Ito, Daisuke Okabe, and Ken Anderson. 2009. Portable Objects in Three Global Cities: The Personalization of Urban Places. In The Reconstruction of Space and Time: Mobile Communication Practices, Rich Ling and Scott W. Campbell (Eds.). 67-87.

[21] Pradthana Jarusriboonchai. 2016. Understanding Roles and User Experience of Mobile Technology in Co-Located Interaction. Ph.D. Dissertation.

[22] Pradthana Jarusriboonchai, Hong Li, Emmi Harjuniemi, Heiko Müller, and Jonna Häkkilä. 2020. Always with Me: Exploring Wearable Displays as a Lightweight Intimate Communication Channel. In Proceedings of the Fourteenth International Conference on Tangible, Embedded, and Embodied Interaction (TEI '20). Association for Computing Machinery, Sydney NSW, Australia, 771-783. https://doi.org/10. 1145/3374920.3375011

[23] Pradthana Jarusriboonchai, Aris Malapaschas, Thomas Olsson, and Kaisa Väänänen. 2016. Increasing Collocated People-s Awareness of the Mobile User-s Activities: A Field Trial of Social Displays. In CSCW '16. ACM Press, 1689-1700. https://doi.org/10.1145/2818048.2819990
[24] Pradthana Jarusriboonchai, Thomas Olsson, Vikas Prabhu, and Kaisa VäänänenVainio-Mattila. 2015. CueSense: A Wearable Proximity-Aware Display Enhancing Encounters. ACM Press, 2127-2132. https://doi.org/10.1145/2702613.2732833

[25] Oliver P. John, Laura P. Naumann, and Christopher J. Soto. 2008. Paradigm Shift to the Integrative Big Five Trait Taxonomy. Handbook of personality: Theory and research 3, 2 (2008), 114-158.

[26] Oskar Juhlin. 2015. Digitizing Fashion: Software for Wearable Devices. interactions 22, 3 (April 2015), 44-47. https://doi.org/10.1145/2754868

[27] Hsin-Liu (Cindy) Kao and Chris Schmandt. 2015. MugShots: A Mug Display for Front and Back Stage Social Interaction in the Workplace. ACM Press, 57-60. https://doi.org/10.1145/2677199.2680557

[28] Lisa Kleinman, Tad Hirsch, and Matt Yurdana. 2015. Exploring Mobile Devices as Personal Public Displays. In MobileHCI '15. ACM Press, 233-243. https: //doi.org/10.1145/2785830.2785833

[29] Mikko Kytö and David McGookin. 2017. Augmenting Multi-Party Face-toFace Interactions Amongst Strangers with User Generated Content. Computer Supported Cooperative Work (CSCW) 26, 4-6 (Dec. 2017), 527-562. https: //doi.org/10.1007/s10606-017-9281-1

[30] Mikko Kytö and David McGookin. 2017. Investigating User Generated Presentations of Self in Face-to-Face Interaction between Strangers. International fournal of Human-Computer Studies 104 (Aug. 2017), 1-15. https://doi.org/10.1016/j.ijhcs. 2017.02.007

[31] Airi Lampinen, Donald McMillan, Barry Brown, Zarah Faraj, Deha Nemutlu Cambazoglu, and Christian Virtala. 2017. Friendly but Not Friends: Designing for Spaces Between Friendship and Unfamiliarity: Short Paper. ACM Press, 169-172. https://doi.org/10.1145/3083671.3083677

[32] Liber8tech Team. 2018. Tago Arc: One E Ink Bracelet with Endless Designs. Retrieved 2019-09-20 from http://www.indiegogo.com/projects/1116628/fblk

[33] Andrés Lucero. 2015. Using Affinity Diagrams to Evaluate Interactive Prototypes. In Human-Computer Interaction. Springer, 231-248.

[34] Angella Mackey, Ron Wakkary, Stephan Wensveen, and Oscar Tomico. 2017. "Can I Wear This?” Blending Clothing and Digital Expression by Wearing Dynamic Fabric. International fournal of Design 11, 3 (2017), 15. http://www.ijdesign.org/ index.php/IJDesign/article/view/3177/794

[35] Julia M. Mayer, Starr Roxanne Hiltz, Louise Barkhuus, Kaisa Väänänen, and Quentin Jones. 2016. Supporting Opportunities for Context-Aware Social Matching: An Experience Sampling Study. In CHI '16. ACM Press, 2430-2441. https://doi.org/10.1145/2858036.2858175

[36] J. McCarthy. 2002. Using Public Displays to Create Conversation Opportunities. In Proceedings of Workshop on Public, Community, and Situated Displays at CSCW'02.

[37] Robb Mitchell and Thomas Olsson. 2017. Barriers for Bridging Interpersonal Gaps: Three Inspirational Design Patterns for Increasing Collocated Social Interaction: Full Paper. ACM Press, 2-11. https://doi.org/10.1145/3083671.3083697

[38] Vivian Genaro Motti and Kelly Caine. 2015. Users' Privacy Concerns About Wearables. In Financial Cryptography and Data Security (Lecture Notes in Computer Science), Michael Brenner, Nicolas Christin, Benjamin Johnson, and Kurt Rohloff (Eds.). Springer Berlin Heidelberg, 231-244.

[39] Tien T. Nguyen, Duyen T. Nguyen, Shamsi T. Iqbal, and Eyal Ofek. 2015. The Known Stranger: Supporting Conversations between Strangers with Personalized Topic Suggestions. ACM Press, 555-564. https://doi.org/10.1145/2702123.2702411

[40] Thomas Olsson, Pradthana Jarusriboonchai, Paweł Woźniak, Susanna Paasovaara, Kaisa Väänänen, and Andrés Lucero. 2019. Technologies for Enhancing Collocated Social Interaction: Review of Design Solutions and Approaches. Comput Supported Coop Work (Feb. 2019). https://doi.org/10.1007/s10606-019-09345-0

[41] Susanna Paasovaara, Kaisa Väänänen, Aris Malapaschas, Ekaterina Olshannikova, Thomas Olsson, Pradthana Jarusriboonchai, Jiří Hošek, and Pavel Mašek. 2018. Playfulness and Progression in Technology-Enhanced Social Experiences Between Nearby Strangers. In Proceedings of the 10th Nordic Conference on Human-Computer Interaction (NordiCHI '18). ACM, New York, NY, USA, 537-548. https://doi.org/10.1145/3240167.3240212

[42] Aditi Paul. 2019. How Are We Really Getting to Know One Another? Effect of Viewing Facebook Profile Information on Initial Conversational Behaviors Between Strangers. The fournal of Social Media in Society 8, 1 (May 2019), 249-270. http://thejsms.org/tsmri/index.php/TSMRI/article/view/467

[43] Eric Paulos and Elizabeth Goodman. 2004. The Familiar Stranger: Anxiety, Comfort, and Play in Public Places. In Proceedings of the SIGCHI Conference on Human Factors in Computing Systems (CHI '04). ACM, New York, NY, USA, 223-230. https://doi.org/10.1145/985692.985721

[44] Jennifer Pearson, Simon Robinson, and Matt Jones. 2015. It's About Time: Smartwatches as Public Displays. In CHI '15. ACM Press, 1257-1266. https: //doi.org/10.1145/2702123.2702247

[45] Pins Collective. 2018. Pins Collective. Retrieved 2020-10-13 from https://www. kickstarter.com/projects/pinscollective/pins-collective

[46] Inka Rantala, Ashley Colley, and Jonna Häkkilä. 2018. Smart Jewelry: Augmenting Traditional Wearable Self-Expression Displays. In Proceedings of the 7th ACM International Symposium on Pervasive Displays - PerDis '18. ACM Press, Munich, Germany, 1-8. https://doi.org/10.1145/3205873.3205891 
[47] Andrew Reilly and Eirik J. Saethre. 2013. The Hankie Code Revisited: From Function to Fashion. Critical Studies in Men's Fashion 1, 1 (Oct. 2013), 69-78. https://doi.org/10.1386/csmf.1.1.69_1

[48] Paula Roinesalo, Juho Rantakari, Lasse Virtanen, and Jonna Häkkilä. 2016. Clothes Integrated Visual Markers as Self-Expression Tool. ACM Press, 617-620. https: //doi.org/10.1145/2957265.2961832

[49] Harvey Sacks and Gail Jefferson. 1995. Lectures on Conversation: Volumes I \& II (1. publ. in one paperback volume 1995, [nachdr.] ed.). Blackwell, Oxford.

[50] Stefan Schneegass, Sophie Ogando, and Florian Alt. 2016. Using On-Body Displays for Extending the Output of Wearable Devices. In Proceedings of the 5th ACM International Symposium on Pervasive Displays - PerDis '16. ACM Press, Oulu, Finland, 67-74. https://doi.org/10.1145/2914920.2915021

[51] Jan Seeburger, Marcus Foth, and Dian Tjondronegoro. 2015. Digital Design Interventions for Creating New Presentations of Self in Public Urban Places. In Citizen's Right to the Digital City, Marcus Foth, Martin Brynskov, and Timo Ojala (Eds.). Springer Singapore, Singapore, 3-21. https://doi.org/10.1007/978-981287-919-6_1

[52] Sophie Charara. 2016. Gemio: Smart Bracelet Light Messages Are the New Snapchat. https://www.wareable.com/fashion/gemio-smart-bracelet-light- messages-new-snapchat

[53] Sakari Tamminen and Elisabet Holmgren. 2016. The Anthropology of Wearables: The Self, The Social, and the Autobiographical. Ethnographic Praxis in Industry Conference Proceedings 2016, 1 (Nov. 2016), 154-174. https://doi.org/10.1111/15598918.2016 .01083

[54] Theresa Jean Tanenbaum, Amanda M. Williams, Audrey Desjardins, and Karen Tanenbaum. 2013. Democratizing Technology: Pleasure, Utility and Expressiveness in DIY and Maker Practice. In Proceedings of the SIGCHI Conference on Human Factors in Computing Systems - CHI '13. ACM Press, Paris, France, 2603. https://doi.org/10.1145/2470654.2481360

[55] Oscar Tomico, Lars Hallnäs, Rung-Huei Liang, and Stephan A G Wensveen. 2017. Towards a Next Wave of Wearable and Fashionable Interactions. IfDesign 11, 3 (2017), 6.

[56] Jason Wiese, Patrick Gage Kelley, Lorrie Faith Cranor, Laura Dabbish, Jason I. Hong, and John Zimmerman. 2011. Are You Close with Me? Are You Nearby?: Investigating Social Groups, Closeness, and Willingness to Share. In Proceedings of the 13th International Conference on Ubiquitous Computing. ACM, 197-206. 